\title{
Role of Information and Communication Technologies (ICTs) in Enhancing Food Utilization among Smallholder Farmers' Households in Northern Nigeria
}

\author{
Olayemi S. Sennuga ${ }^{1,3}$, Richard N. Baines ${ }^{1}$, John S. Conway ${ }^{1} \&$ Rhiannon K. Naylor ${ }^{2}$. \\ ${ }^{1}$ School of Agriculture Food and Environment, Royal Agricultural University, Stroud Road, Cirencester, \\ Gloucestershire, United Kingdom, GL7 6JS \\ ${ }^{2}$ School of Rural Land Use and Management, Royal Agricultural University, Stroud Road \\ Cirencester, Gloucestershire, United Kingdom, GL7 6JS \\ ${ }^{3}$ Federal Ministry of Agriculture and Rural Development, Abuja, Nigeria. \\ *E-mail of the corresponding Author: dr.yemisennuga@yahoo.co.uk
}

\begin{abstract}
Information and Communication Technologies (ICTs) are attracting global attention because of their unprecedented potential to bring about astounding improvement. The numerous advantages presented by ICTs can be employed towards the enhancement of rural households' capabilities in attaining sufficient, safe and nutritious food. This paper seeks to establish the potency of ICTs in enhancing the food utilization among smallholder households in Northern Nigeria. Data were collected through a structured questionnaire administered to 120 smallholders. The results show that smallholders consider that food utilization was inadequate (80.9\%); however, they acknowledged that ICTs could play a significant role in enhancing food utilization. The findings further reveal that the following were ranked first to fifth by household heads: disseminating appropriate information about food crops (98.6\%), improving purchasing power and market price $(94.1 \%)$, enhancing decision-making regarding food $(89.5 \%)$, improving food distribution practices $(81.1 \%)$ and improving cultural and individual food choice (77.6).
\end{abstract}

Keywords: ICTs, Food utilization, Smallholder farmer households, Nigeria

DOI: $10.7176 / \mathrm{IKM} / 10-1-05$

Publication date: January $31^{\text {st }} 2020$

\section{Introduction}

The general trend in global food security during the last century was characterized by a change from shortage to surpluses, resulting mainly in food affluence in the developed world. However, Sub-Saharan African (SSA) has faced multiple problems, the most fundamental one being improving the lives of $30 \%$ of its population that suffers from extreme poverty and food insecurity (Balasubramanian et al. 2007). Some 70\% of the population in Sub-Saharan Africa lives off farming and connected activities, and most studies of rural development unanimously consider that the crucial condition for achieving food security is relevant information (Kivunike et al. 2011; Fawole and Olajide 2012; Fasoyiro and Taiwo 2012; Rasul and Hussain 2015). Timely provision of appropriate information and knowledge are key determinants in ensuring food security and ICTs have the potential to make available the most up-to-date information necessary for improving food security (Lashgarara et al. 2010). Unfortunately, the present generation of smallholder farmers are considered to have little or no predisposition and competence to access and absorb electronically-distributed relevant information on agricultural technologies and market information. Nevertheless, their more-enlightened and knowledgeable children may perhaps be expected to be both proficient and interested to do so as they are growing up in a more electronic age.

According to the definition put forward by the FAO World Food Summit (1996), food security exists when all people at all times have physical and economic access to sufficient, safe, and nutritious food that meets their dietary needs and food preferences for an active and healthy life (FAO 1996; FAO 2009). Food security rests on four major pillars namely food availability, access to food, the utilization of food and stability. Furthermore, food availability is defined as sufficient quantities of food available on a consistent basis (Thomas et al. 2014); food access is having adequate resources to obtain appropriate food for a nutritious diet, food utilization is based on knowledge of basic nutrition and care, as well as adequate water and sanitation (WHO 2012) and embraces the suitable biological uses of food that depend on a household knowledge of techniques for storing and processing food and basic principles of nutrition and caring for children (Lashgarara et al. 2010; Adegbola 2011); finally stability refers to the ability to obtain food over time while Food insecurity can be transitory, seasonal, or chronic (FAO 1997).

The use of ICTs is one approach to providing relevant information. ICT is an umbrella term that includes any communication device or application, encompassing: radio, television, mobile phones, computer and network hardware and software, satellite system and so on. According to the World Bank (2002), ICTs consist of hardware, software, networks, and media for collection, storage, processing, transmission and presentation of information (voice, data, text and image). They are veritable tools that are used for linking, disseminating and handling information beyond that of physical proximity.

In the recent past, numerous policies and interventions have been piloted by the Nigerian Federal Government in its efforts to ensure food security and, to combat hunger and malnutrition by providing adequate food for the people and ensuring food 
security for all. These include: Operation Feed the Nation (OFN), Green Revolution (GR); Directorate of Food, Roads and Rural Infrastructure (DFRRI), Special Programme for Food Security (SPFS), Root and Tuber Expansion Programme, Fadama Development Project and Community-based agricultural and rural development to mention but a few (Sennuga 2012; Ojo and Adebayo 2012; Eme et al. 2014).

The broad objective of this study was to identify the potential of ICTs for enhancing food utilization of smallholder households in Northern Nigeria based on theoretical framework adapted from Lashgarara (2010 Fig 1). The specific objectives were to:

1. Examine the socio-economic characteristics and demographics of smallholder farmers.

2. Analyse the situation of food utilization in smallholder farmer's households

3. Ascertain the role of ICTs in enhancing food utilization among smallholder farmer's households.

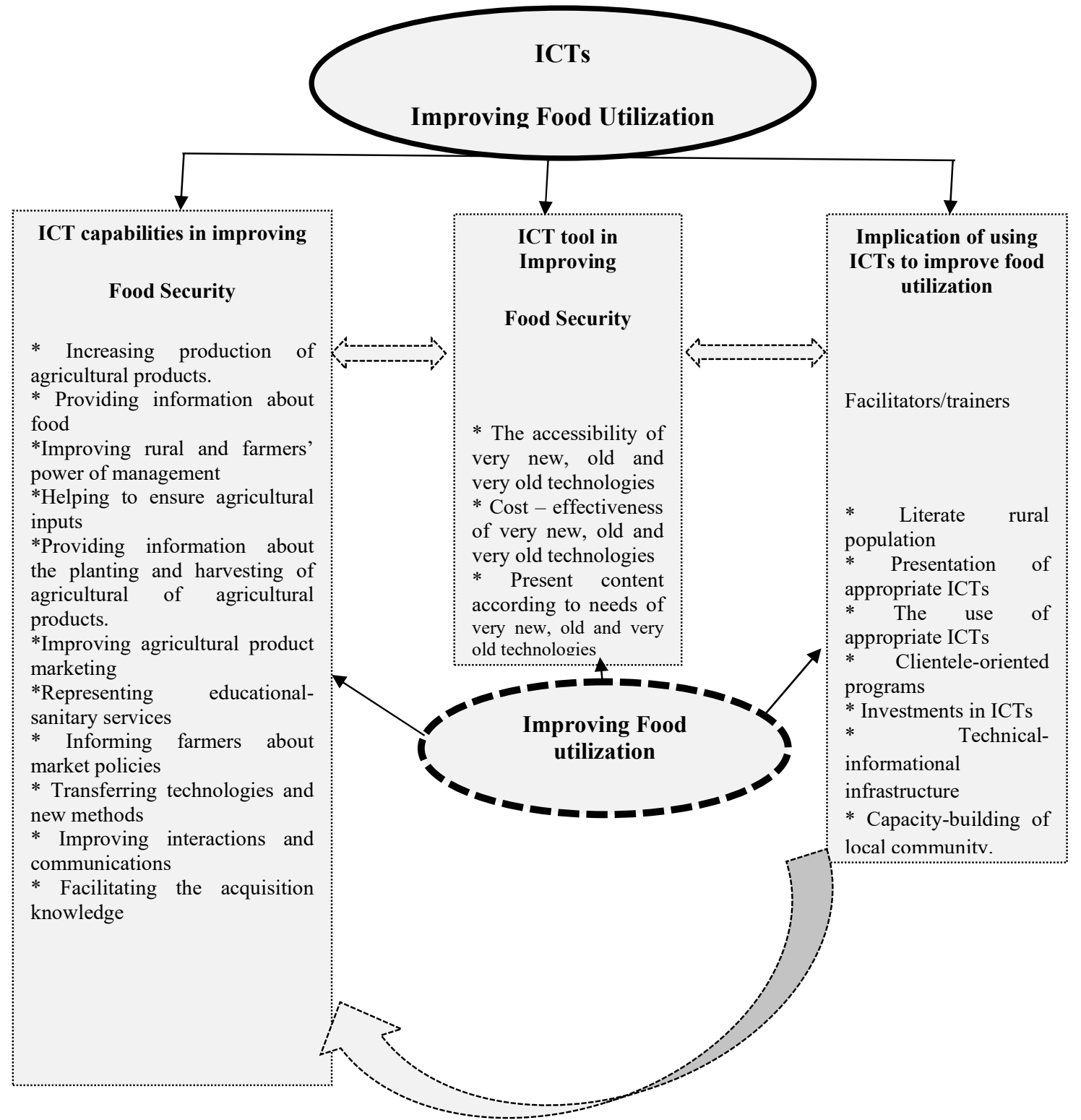

Figure 1: The theoretical framework of the study. Adapted from Lashgarara (2010)

\subsection{Research Approach}

This research was conducted in two randomly selected Local Government Areas of Kaduna State, Northern Nigeria (figure 2); however, the two rural communities (Shika and Basawa) were purposely selected out of 18 villages because of their age-long agricultural practice and presence of adoption practices noted there. From each 
village, 60 farming households were randomly selected giving a total of 120 smallholder farmers. A rural adapted household survey was the major instrument used for data collection. Closed and open ended questions plus some ranking questions were asked to seek the opinion of farmers about food utilisation. The survey was pre-tested before collecting the actual data to check the reliability of the interview schedule. The study independent variables consist of ICT effectiveness in enhancing food utilization, ICT devices and significance of the use of ICTs for improving food utilization. The dependent variable for this was the opinion of smallholder farmers with regarding food utilization.

The data collected was analysed through descriptive and inferential statistics. The software SPSS version 24 was used and included frequency distribution, percentage and correlation analysis.

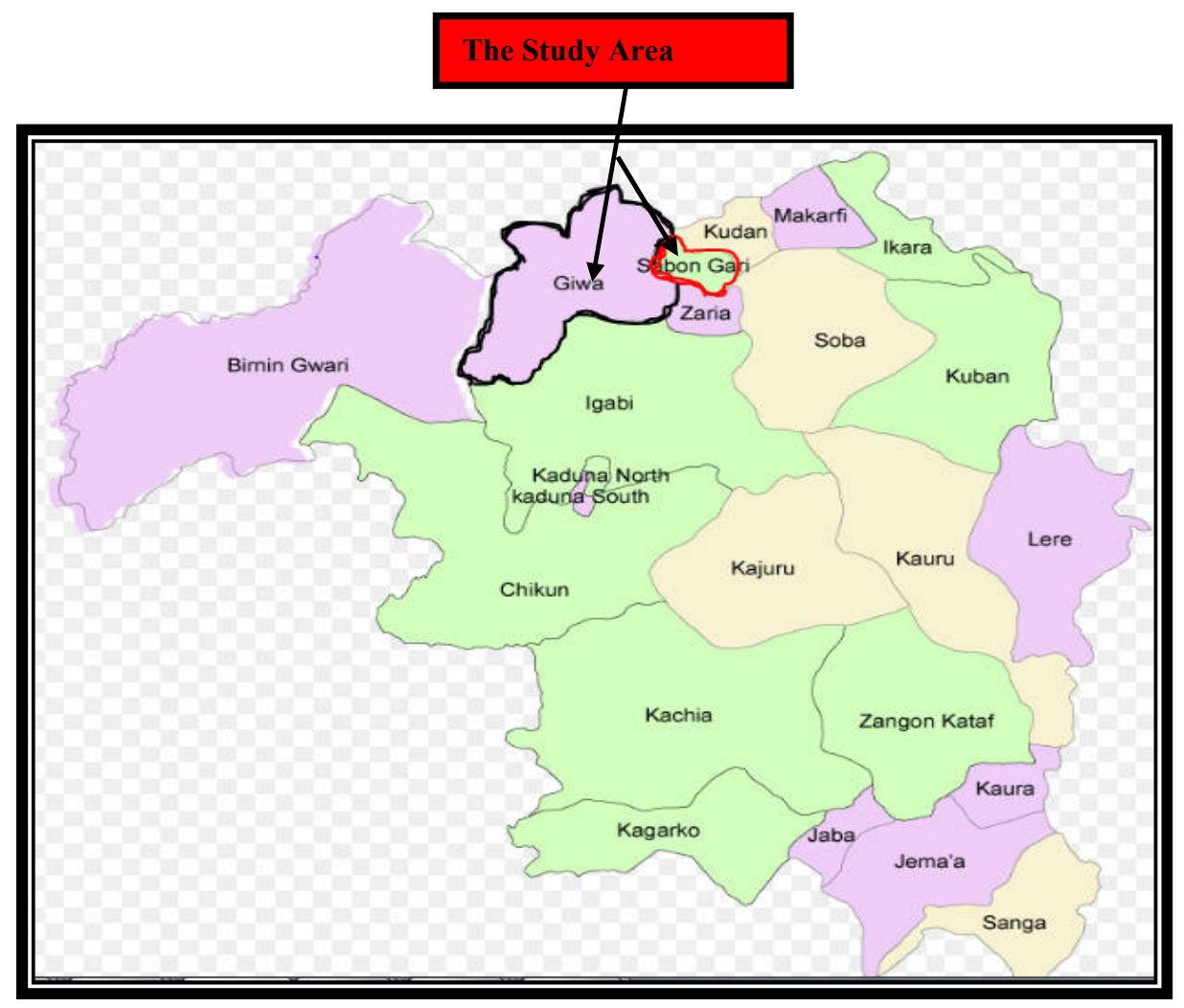

Figure 3: Map of the Study Area showing Giwa and Sabon Gari LGA, Kaduna State.

\section{Results and Discussion}

\subsection{Profiling smallholder farmers:}

The results of the study showed that all the respondents were males; this is because the cultural traditions of the study area do not allow females to be actively involved in farming activities. Furthermore, nearlyone-third (31.7\%) of the respondents were between 31-40years old followed by $27.5 \%$ who were between 41-50 years old; in terms of new entrants to smallholding, just under $15.8 \%$ were between 20 and 30 years old (Table 1). Overwhelming majorities $(96.7 \%)$ of the respondents were married with half of these households having 10 or fewer members; the remainder had larger families of 21 plus members reflecting polygamy within these communities.

In terms of the education of the household heads some two thirds had no education or only primary education, one quarter had secondary education and only some $7.5 \%$ had tertiary education (Table 1). When family education is considered there is evidence of investment in the next generation with less than $4 \%$ having no 
education (probably babies and infants), 55\% having primary education and $36 \%$ going on to secondary education (Table 1).

Table 1: Distribution of the personal and demographic characteristics of smallholder farmers $(n=120)$

\begin{tabular}{|c|c|}
\hline Variables & Percentage \\
\hline \multicolumn{2}{|l|}{ Age (years) } \\
\hline $20-30$ & 15.8 \\
\hline $31-40$ & 31.7 \\
\hline $41-50$ & 27.5 \\
\hline $51-60$ & 17.5 \\
\hline $61-70$ & 6.7 \\
\hline$>70$ & .8 \\
\hline \multicolumn{2}{|l|}{ Gender (Sex) } \\
\hline Male & 100 \\
\hline Female & 0 \\
\hline \multicolumn{2}{|l|}{ Marital status } \\
\hline Single & 3.3 \\
\hline Married & 96.7 \\
\hline \multicolumn{2}{|l|}{ Household size } \\
\hline$\leq 10$ & 50.8 \\
\hline $11-20$ & 36.4 \\
\hline $21-30$ & 12.1 \\
\hline$>31$ & .7 \\
\hline \multicolumn{2}{|c|}{ Level of education } \\
\hline No education & 25.8 \\
\hline Primary & 40.0 \\
\hline Secondary & 26.7 \\
\hline Tertiary & 7.5 \\
\hline
\end{tabular}

\subsubsection{Food utilization in smallholder households}

The results revealed that an overwhelming majority of the respondents $(80.9 \%)$ acknowledged that the situation of food utilization among the rural households was inadequate (Table 2). Only 14.2\% indicated that the situation was adequate, while $2.5 \%$ and $1.7 \%$ reported outstanding and don't know respectively. These results imply that the situation of food utilization was insufficient and the smallholders were not food secure. A similar result was found by Lashgarara et al. (2010). 
Table 2: Distribution of respondents' opinion about the situation of

food utilization in smallholder among farmers' households $(n=120)$

\begin{tabular}{lc}
\hline Situation & Percentage \\
\hline Don't know & 1.7 \\
Inadequate & 80.9 \\
Adequate & 14.2 \\
Outstanding & 2.5 \\
\hline
\end{tabular}

\section{The role of ICTs in enhancing food utilization in smallholder households}

The results revealed that a very large percentage $(60 \%)$ of the respondents strongly believed that ICTs have the potential and could play a very significant role in improving food utilization among rural households (Table 3 ). A related finding was reported by Babatunde et al. (2007) respectively.

Table 3: Distribution of respondents investigate the role of ICTs in enhancing food utilization of smallholders' farmer's households $(\mathrm{n}=120)$

\begin{tabular}{lc}
\hline Role & Percentage \\
\hline Low & 2.5 \\
Average & 5.8 \\
Strong & 31.7 \\
Very strong & 60.0 \\
\hline
\end{tabular}

A number of factors positively correlated with enhancing food utilization according to smallholders (Table 4); these included: providing information about food crop, enhancing informed decisions about livelihoods, better information and knowledge-exchange, reduction in travel costs, enhancing access to market prices, maintaining relations among rural communities, increasing the nutritional value of food crops, access to radio technologies, enhancing smallholders powers of acquiring knowledge and providing education and training are significant (correlation $<0.01$ ). The ability to contact others in emergency, better access to available credits, providing health-education services and reducing operations costs and robust information were significant $(\mathrm{P}<0.05)$ with the food utilization of smallholders' households.

To ascertain the important role of ICTs in enhancing food utilization among smallholder households, respondent were asked to rank a number of the variables (Figure 4). In terms of importance, appropriate information about food crops was the most important, followed by enhancing ability to make informed decisions about livelihoods, better information and knowledge-exchange, reduction in travel costs, enhancing access to market prices, maintaining relation among rural communities, access to radio technologies, intra and inter business transactions, increase nutritional value of food crops, enhancing smallholder power of acquiring knowledge, providing education and training. In total, when ranking these variables, the result showed that $98.6 \%$ of the respondents believed that ICTs have a significant role to play in improving livelihoods and have the capability to improve the food utilization of the smallholder farmers in Northern Nigeria. This study confirmed the results of Lashgarara et al. (2010), Mago and Mago (2015) and Abu and Soom (2016). 
Table 4: Correlations Coefficient (Pearson) between study variables and enhancing food utilization

\begin{tabular}{lll}
\hline \multicolumn{1}{c}{ Variables } & $\mathbf{r}$ & $\mathbf{p}$ \\
\hline Appropriate information about food crops & $0.401^{* *}$ & 0.002 \\
Household purchasing power and market prices & & \\
Enhancing household decision-making regarding food & $0.374^{* *}$ & 0.000 \\
Improving the processing and cooking of food at home & 0.251 & 0.001 \\
Improving food distribution practices & $0.213^{* *}$ & 0.002 \\
Improving cultural and individual food choices & $0.192^{* *}$ & 0.001 \\
Access to health care, sanitation and knowledge & $0.211^{* *}$ & 0.001 \\
Intra and inter business transactions with traders & $0.139 * *$ & 0.002 \\
Increase nutritional value of food crops & $0.215^{* *}$ & 0.001 \\
Enhancing smallholder power of acquiring knowledge & $0.235^{* *}$ & 0.003 \\
Provide education and training & $0.198^{* *}$ & 0.001 \\
Capacity development among farmers & $0.86^{*}$ & 0.02 \\
Ability to contact others in emergency & $0.79 *$ & 0.03 \\
Better access to avoidable credits & $0.67 *$ & 0.03 \\
Providing health-education services & $0.58^{*}$ & 0.02 \\
Reduce travel and operations cost & $0.49 *$ & 0.04 \\
\hline
\end{tabular}




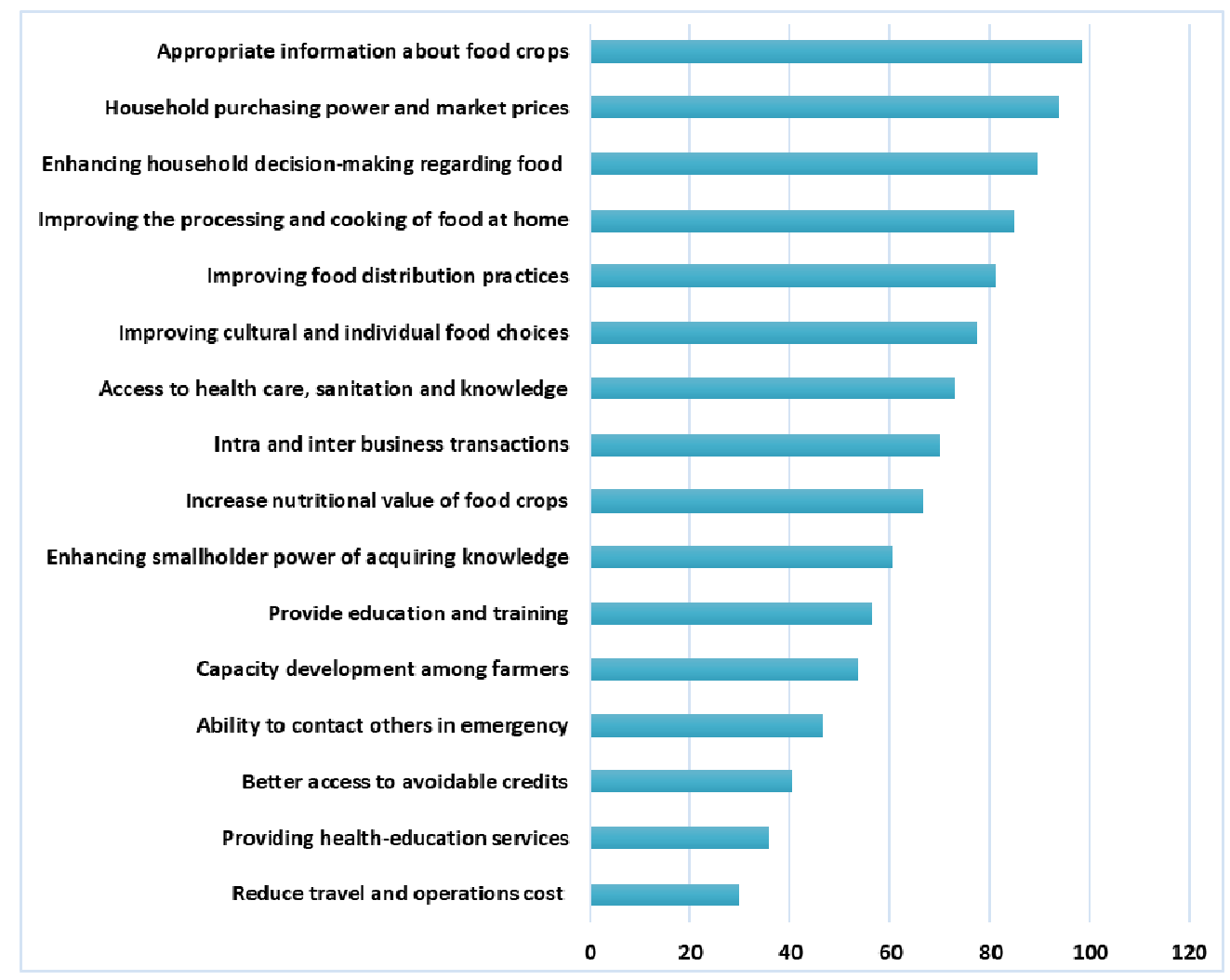

Figure 4: Distribution of respondents according to the role of ICTs in enhancing food utilization among smallholders' farmer's households $(\mathrm{n}=120)$

A number of constraints were identified by smallholder households in relation to food utilization with the lack of credit facilities ranked first (Table 5) followed by soil infertility, unfavourable weather, poverty and so on.

Table 5: Major constraints affecting smallholder rural households food availability $(\mathrm{n}=120)$

\section{Constraint $\quad$ Frequency (F) Percentage}

$\begin{array}{ll}\text { Lack of access to credit facilities } & 93.7\end{array}$

Soil Infertility

81.2

Unfavourable weather/climatic condition

75.4

Poverty

Storage and processing problem crisis

Lack of non-farm income generating activities

Distance away from the main road

Disease and pests

Drought

High food prices

47.1

Multiple responses were allowed 


\section{Conclusion}

The study has explored and identified the potential role of ICTs in enhancing food utilization among smallholder farmer households in Northern Nigeria. Based on the empirical evidence emerging from the analysis of this study, it can be concluded that food availability by the households was inadequate. Smallholder farmers also expressed some major constraints affecting rural household food utilization. The results indicated that demographic and socioeconomic factors influenced the food utilization status of the smallholder households. This means that factors such as educational attainment of the household heads, farm size, household income which mainly derived from subsistence agricultural production with limited participation in non-agricultural activities, large household size also exerted pressure on consumption and food expenditure and worsened food insecurity in households.

The results of this study suggest that to achieve improvement in the food utilization among smallholder households, government should give more consideration to the elimination of illiteracy amongst rural dwellers by providing them with informal education via extension services on nutritional awareness and non-agricultural income generation opportunities. Suitable health care improvement and adequate family planning programmes and awareness could also be made available and implemented to reduce the number of children in households. In addition, the government could give rural households access to consumption and production credits at minimum interest rates. Furthermore, government poverty alleviation programmes should concentrate on boosting the nonagricultural income of smallholders.

Notwithstanding the above, the smallholder farmers do acknowledge ICT's as important tools that can have a substantial role in improving food utilization of the households. This includes by providing the most relevant information about food crops, enhancing the ability to make informed decision about livelihoods, reduction in travel costs, improving direct access to market information which promote the use of yield-augmenting agricultural seed technologies, maintaining relations among rural communities, increasing the nutritional value of food crops, access to radio technologies, enhancing smallholder power of acquiring knowledge and providing education and training for relatively poor educated farmers. Finally, ICTs can also improve the quality of rural life, as well as play a major role in facilitating the processes of integration and transformation of rural communities.

\section{References}

Adegbola, A. J., Awagu, E. F., Kamaldeen, O. S., \& Kashetu, R. Q. (2016). Sorghum: Most under-utilized grain of the semi-arid Africa. Scholarly Journal of Agricultural Science, 3:4, 147-153.

Balasubramanian, V., Sie, M., Hijmans, R.J., \& Otsuka, K., (2007). Increasing rice production in sub-Saharan Africa: challenges and opportunities. Advances in Agronomy, 94, 55-133.

FAO (1997). "The food system and factors affecting household food security and nutrition". Agriculture, food and nutrition for Africa: a resource book for teachers of agriculture.

Rome: Agriculture and Consumer Protection Department.

FAO (2010). Human Energy Requirement, Food and Nutrition Technical Report, Food and Agriculture Organization of the United Nations, Rome

FAO (2009). Regional overview of food insecurity: African food security prospects brighter than ever. Accra, FAO. http://www.fao.org/3/a-i4635e.pdf

FAO (2012). The State of Food Insecurity in the World (Food and Agriculture Organization of the United Nations, Rome

Fasoyiro, S. B. \& Taiwo, K. A. (2012). Strategies for Increasing Food Production and Food Security in Nigeria, Journal of Agricultural and Food Information, 13:4, 338-355

Fawole, O. P. \& Olajide, B. R. (2012). Awareness and Use of Information Communication Technologies by Farmers in Oyo State, Nigeria, Journal of Agricultural \& Food Information, 13, 326-337

Kivunike, F. N., Ekenberg, L., Danielson, M. \& Tusubira, F. F. (2011). Perceptions of the role of ICT on quality of life in rural communities in Uganda, Information Technology for Development, 17:1, 61-80 
Lashgarara, F., Mirdamadi, S.M. \& Hosseini, S.J.F. (2010). Role of Information and Communication Technologies (ICTs) in improving food utilization of Iranian rural households. Journal of Dairying, Foods \& Home Sciences, 29, 210-215

Lashgarara, F., Mirdamadi, S.M. \& Hosseini, S.J.F. (2010). The causal model role of ICTs in food utilization of Iranian rural households. African Journal of Agricultural Research, 5:20, 747-756

Mago, S. and Mago, S. (2015). Information and Communications Technologies (ICTs) and Livelihoods Enhancement in Agro-rural Communities in Zimbabwe: Connections Using the Capabilities Approach, Journal of Communication, 6:1, 93-103

Rasul, G. and Hussain, A. (2015). Sustainable Food Security in the Mountains of Pakistan: Towards a Policy Framework, Ecology of Food and Nutrition, 54, 625-643

Sennuga, S.O. (2012). The Application of Information and Communication Technologies to Small-scale Agriculture in Nigeria. (Unpublished Master's Thesis). University of Reading, Reading, United Kingdom

Thomas, K., Rosenberger, J. G. and Pawloski, L.R. (2014). Food Security in Bombard polis, Haiti, Journal of Hunger \& Environmental Nutrition, 9:2, 230-243

World Bank (2007). World Development Report 2008: Agriculture for Development, World Bank, Washington, DC.

World Bank (2012). World Development Report 2008: Agriculture for Development. World Bank, Washington, DC.siteresources.worldbank.org/.../WDROver2008-ENG.pdf

World Food Summit, (1996). World Food Summit Plan of Action, paragraph 1. In: Rome Declaration on World Food Security and World Food Summit Plan of Action; World Food Summit, 13-17 November 1996, Rome, Italy. Rome, FAO. 43 